\title{
O uso do júri simulado como metodologia ativa na Medicina Veterinária
}

\author{
The use of the mock trial as an active methodology in Vet \\ El uso del jurado simulado como metodología activa en Medicina Veterinaria
}

Recebido: 26/08/2021 | Revisado: 03/09/2021 | Aceito: 09/09/2021 | Publicado: 12/09/2021

\author{
Melissa Sanches Mongelli \\ ORCID: https://orcid.org/0000-0003-4239-336X \\ Universidade Federal de Lavras, Brasil \\ E-mail: melissa.mongelli@estudante.ufla.br \\ Marcos Ferrante \\ ORCID: https://orcid.org/0000-0001-6979-2956 \\ Universidade Federal de Lavras, Brasil \\ E-mail: marcos.ferrante@ufla.br \\ Paulo Henrique Arcas \\ ORCID: https://orcid.org/0000-0002-6535-936X \\ Universidade Federal de Lavras, Brasil \\ E-mail: paulo.arcas@ufla.br
}

\begin{abstract}
Resumo
Atualmente, sabe-se o quão importante e necessário é a formação em um curso superior. No entanto, a maior preocupação dos professores não é somente a qualidade do conteúdo que é repassado, mas também o desenvolvimento do senso crítico. O objetivo da pesquisa é relatar o uso do júri simulado em diferentes cursos e analisar tal metodologia ativa no curso de Medicina Veterinária. A pesquisa foi realizada no ano de 2021. Os dados apresentados foram coletados na literatura disponível nos Periódicos eletrônicos da CAPES: Scopus, Google Acadêmico, Pubmed e Scielo, possuindo como palavras-chaves "Júri simulado" e " veterinária", como também em livros para formulação teórica da revisão. Ao analisar os dados referentes a pesquisa é visto que o uso do júri simulado na medicina veterinária é escasso, porém, é imprescindível a sua utilização nas disciplinas, já que é uma área da saúde, precisando formar profissionais capazes de possuir pensamento crítico e reflexivo, como também, saber agir sobre pressão.
\end{abstract}

Palavras-chave: Ensino; Metodologia ativa; Júri simulado; Farmacologia veterinária; Reprodução bovina.

\begin{abstract}
Currently, it is known how important and necessary training in higher education is. However, the greatest concern of teachers is not only the quality of the content that is passed on, but also the development of a critical sense. The objective of the research is to report the use of the mock trial in different courses and to analyze this active methodology in the Veterinary Medicine course. The research was carried out in the year 2021. The data presented were collected in the literature available in CAPES electronic journals: Scopus, Google Scholar, Pubmed and Scielo, having as keywords " mock trial " and "Veterinary ", as well as in books for theoretical formulation of the review. When analyzing the data referring to the research, it is seen that the use of the mock trial in veterinary medicine is scarce, however, its use in the disciplines is essential, since it is an area of health, needing to train professionals capable of having critical and reflective thinking, as well as knowing how to act under pressure.
\end{abstract}

Keywords: Teaching; Active methodology; Mock trial; Veterinary pharmacology; Bovine reproduction.

\section{Resumen}

Actualmente se conoce la importancia y la necesidad de la formación en la educación superior. Sin embargo, la mayor preocupación de los docentes no es solo la calidad de los contenidos que se transmiten, sino también el desarrollo de un sentido crítico. El objetivo de la investigación es reportar el uso del jurado simulado en diferentes cursos y analizar esta metodología activa en el curso de Medicina Veterinaria. La investigación se realizó en 2021.Los datos presentados fueron recolectados en la literatura disponible en las revistas electrónicas CAPES: Scopus, Google Scholar, Pubmed y Scielo, teniendo como palabras clave " Jurado simulado " y " Veterinaria ", además como en los libros para la formulación teórica de la reseña. Al analizar los datos referentes a la investigación, se ve que el uso del jurado simulado en medicina veterinaria es escaso, sin embargo, su uso en las disciplinas es fundamental, ya que es un área de la salud, necesitando formar profesionales capaces de tener pensamiento crítico y reflexivo, así como saber actuar bajo presión.

Palabras clave: Enseñanza; Metodología activa; Jurado simulado; Farmacología veterinaria; Reproducción bovina. 


\section{Introdução}

Atualmente, sabe-se o quão importante e necessário é a formação em um curso superior. Segundo Kleber \& Trevisan, 2010, as pessoas buscam o ensino superior como uma ferramenta que lhe permitirá realização pessoal e, consequentemente, maior empregabilidade e maiores salários. Porém, os jovens estão inseridos em um mundo versátil e tecnológico, dificultando o processo de aprendizagem (Lemos \& Feitosa, 2020), como também a capacidade de adquirir determinado conhecimento e habilidades é multifatorial, envolvendo fatores acadêmicos, aspectos sociais, familiares e institucionais (Santos \& Neto, 2021). Além disso, a maior preocupação dos professores não é somente a qualidade de conteúdo que é transmitido para seus alunos, mas também o desenvolvimento profissional e reflexivo de senso crítico, pois tal progresso facilita a inserção no mercado de trabalho.

Devido a isso, no ano de 1980 foram adotadas metodologias ativas (MA), as quais foram instituídas com o objetivo de facilitar e maximizar o processo de aprendizagem e estimular o aluno a desenvolver habilidades diversas (Lemos \& Feitosa, 2020). As MA são concepções educativas que estimulam processos crítico-reflexivos, no qual o educando participa e se compromete com seu aprendizado, colocando o aluno no centro do processo de ensino-aprendizagem (Gil, 2013). De acordo com Lemos \& Feitosa, 2020, as MA permitem que ocorra interação, formulação de hipóteses e construção do conhecimento de forma ativa, consequentemente, a aprendizagem ocorre quando o aluno interage com o assunto estudado. Neste sentido, os professores passaram a utilizar MA com uma função mediadora na aquisição dos conhecimentos e saberes científicos que os estudantes deverão adquirir para o exercício da prática profissional.

Professores e especialistas do ensino desenvolveram várias estratégias que colocam os estudantes em situações de aprendizagem participativa a partir de MA. Uma dessas estratégias visa o acesso dos alunos às informações necessárias para a construção dos conhecimentos para a produção dos argumentos que serão utilizados durante uma atividade de júri simulado (Vieira \&, 2014). O objetivo dessa estratégia é despertar nos alunos o pensamento crítico e reflexivo, independente do tema abordado. Além disso, trazer para o ambiente de ensino atividades dinâmicas, promovendo aulas mais interessantes e de hábil conhecimento.

O júri simulado é uma estratégia que leva os alunos a experimentarem algum aspecto da realidade e a assumirem papéis existentes na vida real (Gil, 2013). De acordo com Abepirense, \&, 2014, o júri simulado consiste em uma atividade multidisciplinar e dinâmica simulando um tribunal judiciário. Tal estratégia auxilia na formulação do pensamento crítico e reflexivo e também permite que os alunos ampliem a prática de oratória em público, de organização de ideias e argumentação. Correlacionando a MA com o curso de Medicina Veterinária, sabe-se que os cursos relacionados à saúde necessitam ainda mais do profissionalismo crítico, pois é preciso formar profissionais capazes de observar, interpretar e intervir na realidade de forma ética, e pautado no conhecimento científico sendo um desafio e uma grande responsabilidade para o corpo docente, uma vez que estamos falando em lidar com vidas (Gil, 2013).

O objetivo do trabalho é revisar a utilização do júri simulado como metodologia ativa no progresso da educação dos estudantes, avaliando a evolução dos alunos em relação ao pensamento crítico e reflexivo e também da eficácia do ensino. Além disso, expor o uso de tal MA no curso de Medicina Veterinária e correlacionar os dados contidos na literatura para utilizar tal MA nas demais disciplinas.

\section{Coleta de Dados}

A pesquisa foi realizada no período de janeiro a agosto de 2021. Os dados apresentados foram coletados na literatura disponível nos Periódicos eletrônicos da CAPES: Scopus, Google Acadêmico, Pubmed e Scielo, possuindo como palavraschaves "Júri simulado" e " veterinária", como também em livros para formulação teórica da revisão. Para a análise da 
bibliografia encontrada foram incluídos critérios de aceitação (I) trabalhos originais publicados entre 2010 a 2021; (II) trabalhos descritivos abordando júri simulado; (III) relatos do uso do júri simulado na medicina veterinária; (IV) escrita em inglês, espanhol ou português. Para os critérios de exclusão foram utilizados: (I) artigos incompletos que não apresentavam o texto, autores ou/e título completo; (II) falta de informação sobre júri simulado.

\section{Desenvolvimento}

\section{TEORIA DO JÚRI SIMULADO}

Em virtude do avanço tecnológico e a popularização do acesso à informação, os métodos de aprendizagem demandaram mudanças tanto no ensino básico como nas universidades (Lemos \& Feitosa, 2020). Além disso, de acordo com Veiga \& Fonseca, 2018, as MA criadas devem suprir uma 'sociedade em rede", no qual o ensino não é mais considerado individual, mas sim coletivo. Para isso, uma das metodologias criadas para atender a demanda da sociedade é o júri simulado, o qual é uma proposta didático-pedagógica que simula um tribunal judiciário para argumentarem sobre um determinado assunto (Veiga \& Fonseca, 2018) É composto por juiz, vítima(s), advogado(s) de acusação, testemunha(s) de acusação, réu(s), advogado(s) de defesa, testemunha(s) de defesa e júri popular, porém, a composição pode variar de acordo com o discente (Veiga \& Fonseca, 2018).

O professor da disciplina geralmente assume o papel de moderador, estabelecendo o tema, o tempo de cada personagem durante a argumentação e a divisão dos alunos em grupos, instituindo cada papel do júri a um determinado grupo de estudantes (Merlo, 2019). Já os alunos são responsáveis na preparação do estudo, pesquisando sobre o tema proposto e desenvolvendo argumentos representativos para persuasão dos integrantes dos grupos opostos (Merlo, 2019; Veiga \& Fonseca, 2018). Salienta-se que durante a discussão dos argumentos, o professor deve atuar como animador, maximizando o desenvolvimento de argumentos sólidos para o debate e instigando os alunos a refletirem sobre o tema escolhido (Merlo, 2019).

Dessa forma, segundo Anastasiou \& Alves, 2012, o júri simulado possibilita a realização de inúmeras operações de pensamento, como a defesa de ideias, argumentação, julgamento, persuasão e tomada de decisão. É uma estratégia que oportuniza o envolvimento de todos para além da sala de aula, e permite a construção de conhecimentos e estabelecimento de senso crítico. Além disso, tal estratégia induz os estudantes ao aprofundamento do tema, consequentemente, na melhoria da eficiência do ensino, como também na habilidade argumentativa de forma pública, já que, é por meio dos argumentos estabelecidos que os estudantes conseguiram atingir a persuasão do grupo rival (Lemos \& Feitosa, 2020). No que se refere ao meio científico, o júri simulado permite a vivência da prática científica, no sentido da defesa de suas ideias, debater e posicionar-se (Merlo, 2019).

É visto que metodologias tradicionais, como, palestras e pacotes de aprendizagem, proporcionam troca de conhecimento passivo, e portanto, possuem recursos limitados que diminuem a eficácia do aprendizado (White, 2015). A escolha por MA, como a simulação, requer maior demanda e concentração dos alunos. Há pesquisa que comprova que os estudantes são mais propensos a absorver conhecimento quando são baseados em experiências reais, em relação aos métodos tradicionais (Persad \&, 2008).

\section{JÚRI SIMULADO EM OUTRAS ÁREAS}

O júri simulado vem sendo utilizado por várias áreas do conhecimento, seja no ensino escolar, universitário, empresarial, e médico. No entanto, todas as áreas citadas possuem um objetivo em comum: maximizar a eficiência da aprendizagem e desenvolver senso crítico e argumentativo nos participantes. Dessa forma, foram selecionadas duas referências 
de diferentes áreas de conhecimento, para exemplificar a utilização do júri simulado.

(I) Ensino de Vigilância em Saúde (Lima \&, 2020)

A atividade foi realizada no curso de Medicina contendo 60 discentes e 2 docentes, estabeleceram 4 horas de duração, e o tema proposto foi em relação ao rompimento da barragem do município de Mariana em 2015 e os danos à saúde da população dessa área. Os alunos foram separados em grupos de acordo com o papel do júri determinado: júri popular (12 alunos), escrivães (12 alunos), acusações ( 8 promotores públicos e 6 testemunhas), defesa (8 advogados e 6 testemunhas) e peritos ( 4 - acusando e 4 defendendo), o réu da ação foi a Vale Mineradora e os juízes os docentes. O julgamento foi iniciado pelo juiz ao ler o objetivo da acusação, depois vieram os promotores, os peritos e as testemunhas (Fig 1). Logo após vieram a defesa, com as mesmas três fases para argumentação. Salienta-se que foram realizadas duas rodadas com o mesmo tempo (Fig 1). Ambos os grupos selecionaram indivíduos para participarem da arguição, e entre os 60 participantes, 28 tiveram voz ativa na atividade. Durante a discussão foram levantadas questões relacionadas à Vigilância em Saúde e seus âmbitos Epidemiológico, Sanitário e Ambiental. Ao final da simulação o júri se reuniu e concluíram que a defesa apresentou vários argumentos válidos, porém, sem muito aprofundar na saúde pública. Já a acusação aprimorou os conhecimentos na saúde da população e vigilância sanitária, sendo considerada vitoriosa. Os alunos participantes responderam o questionário elaborado por docentes e os resultados foram positivos e satisfatórios, com a intenção de melhorar para as próximas atividades.

Figura 1: Fluxograma da metodologia do júri simulado

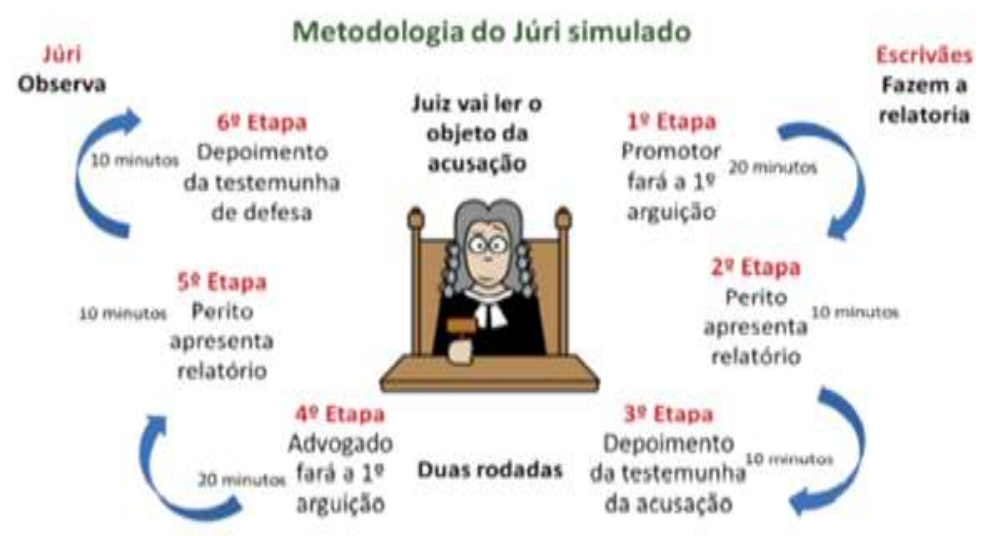

Fonte: Lima et al., (2020).

(II) Formação de Professores de Física (Vieira et al., 2014)

O júri simulado foi atribuído ao curso de Pesquisa e Prática de Ensino de Física, com duração de dois dias (120 minutos) na carga horário de todo o curso (26 horas) e obrigatório para todos os alunos da Licenciatura em Física. O tema proposto foi sobre ligações elétricas irregulares presentes em residências brasileiras e estabelecimentos comerciais, denominadas popularmente como ''gatos'. Os participantes foram realocados em grupos contra ou à favor do ''gato', porém, ocorria alternância entre os grupos, de modo que todos tiveram a oportunidade de defender e atacar os dois lados do debate. Os júris foram divididos por secções, ou seja, um grupo começa a colocação de um argumento e era rebatido para o outro grupo, até que o professor (juiz) julgava que ocorreu saturação de argumentos e iniciava-se outra secção. Ao final do curso, observouse que a atividade foi promissora e auxiliou os licenciados na absorção do conteúdo, como também, comprovou que mesmo formulando argumentos contrários à sua opinião, foram capazes de oferecer evidências e justificativas consistentes. 
(III) Ensino da ética médica (Savari \&, 2013)

Para o ensino e desenvolvimento da ética médica foi proposto o uso do júri simulado para alunos do sétimo ano de medicina (211 pessoas), cursando a disciplina de ética médica na grade curricular. Em um primeiro momento, escolheu-se por livre e espontânea vontade sete alunos do curso para serem os protagonistas da simulação, sendo que havia os responsáveis pela apresentação, denunciante, denunciado, advogados de ambas as partes, relatores e revisores. Além disso, a direção do projeto foi dirigida por um presidente, vice-presidente e secretário, os quais eram constituídos por professores da disciplina. Nota-se que o restante da turma participou como conselheiros, com direito à voz e voto. Após a escolha, planejou-se uma situação real dos conselhos regionais de medicina. Ao final da simulação, os alunos responderam questionários sobre o desenvolvimento do conhecimento sobre ética médica e verificou-se que o júri simulado é importante neste contexto por propiciar maior tempo de exposição da disciplina com os alunos e auxiliar na formação profissional e social de cada estudante.

(IV) O sistema único de saúde em julgamento no curso de enfermagem (Silva Filho \&, 2015).

Devido à preocupação da função social da universidade e da formação de cidadãos comprometidos com a realidade, a UFFS propôs a utilização da metodologia do júri simulado para alunos do primeiro período do curso de enfermagem, focados na disciplina "'Fundamentos de Saúde Pública". A turma possuía 54 pessoas e foi dividida em três grupos: acusação do SUS; defesa do SUS e jurados para o veredicto final. O responsável pela disciplina orientou os alunos a realizarem pesquisas para sustentarem a discussão durante a simulação. No dia do julgamento, cada grupo teve 30 minutos para expor os argumentos e discutirem entre os grupos. Após a simulação, os jurados analisaram cada argumento e concluíram a sessão do júri. De forma panorâmica, os alunos foram avaliados em relação a eficiência da MA, observou-se que foi proveitosa, visto que instigou a autonomia de cada um nas pesquisas e socialização com a equipe. Além disso, os autores citam que tal MA pode desenvolver futuros enfermeiros para promover mudanças no SUS.

(V) Aprendizagem significativa em química orgânica por meio da temática automedicação (Reppold \&, 2021)

A presente pesquisa justifica o uso do júri simulado como ferramenta complementar de ensino-aprendizagem de forma remota, devido à manifestação de desânimo e reclamação por parte dos alunos sobre o ensino de química orgânica, que por vezes limita-se à aprendizagem mecânica. A primeira simulação realizada teve enfoque na comercialização da dipirona no Brasil. A turma possuía 16 alunos e foi dividida em: (1) promotoria da Joana - apontava os erros cometidos pela ANIVSA; (2) defensoria da ANIVISA - direito de respostas sobre as acusações; (3) promotoria da ANVISA - acusando as irresponsabilidades praticas pela Joana e (4) defensoria da Joana - resguardando a cliente. A segunda simulação focou nos contaminantes emergentes, no qual a turma de 16 alunos, foi divisa em 12 para o júri popular e quatro alunos para o corpo jurídico: (1) promotoria da ANVISA; (2) defensoria da COMUSA; (3) promotoria da COMUSA e (4) defensoria da ANVISA. Em ambas as simulações ocorreu a discussão e o julgamento final, por fim realizou-se a avaliação individual sobre a metodologia aplicada. Os pesquisadores apresentam a importância do júri simulado para o engajamento dos alunos no contexto do ensino remoto, além da relevância da na construção de estratégias de ensino opostas a aprendizagem memorística do tema.

\section{JURI SIMULADO NA VETERINÁRIA}

Historicamente a Medicina Veterinária surgiu como área do conhecimento promotora da saúde dos animais, aumentando a produtividade de rebanhos e plantéis, como também permitindo bem estar e elevação da estimativa de vida de pequenos animais (Gomes, 2017). Porém, com o passar dos anos surgiu a medicina preventiva, a qual se preocupa com a saúde pública dos seres humanos, com controle e vigilância de zoonoses e pesquisas integradas entre saúde humana e animal (Costa, 2011). 
Dessa forma, é visto que independente da área de atuação do médico veterinário, precisa-se de conhecimento que vai além da grade curricular proposta nos cursos de veterinária, ou seja, formação de um sujeito crítico e reflexivo, que saiba argumentar e se posicionar a favor ou contra algum assunto. Podem ser citados alguns exemplos demonstrando a importância de tais fatores citados: (I) Veterinário empregado em empresas de produtos veterinários - é visto que o conhecimento técnicocientífico não é o suficiente, é necessário que o veterinário consiga persuadir os consumidores que o produto vendido é eficaz; (II) Veterinário inserido na pesquisa - com o desenvolvimento de novas ideias, deve-se atribuir excelente capacidade argumentativa para convencer a sociedade que o pensamento proposto é viável; (III) Veterinário empregados no MAPA durante a inspeção de alimentos de origem animal, além do conhecimento teórico-prático sobre inspeção e também legislação, devem obter senso crítico sobre cada situação vivenciada.

À vista disso, a utilização do júri simulado na graduação de medicina veterinária pode ser considerada uma ferramenta útil para desenvolver todos os fatores já citados. O estudo de Prado \& Silva (2017) aborda o uso da simulação em duas turmas de graduandos de medicina veterinária (terceiro e nono período), com as correspondentes disciplinas, Microbiologia e Equideocultura. O número de alunos em cada turma era alto (60) e por isso, foram formados grandes subgrupos de acusação, defesa e jurados. Os temas propostos foram considerados polêmicos: utilização de antibióticos, utilização de animais de tração e as provas equestres, com maior ênfase para a vaquejada. O tempo destinado aos alunos para pesquisa e preparação da argumentação foi em um intervalo de duas a três semanas. Na execução da simulação, o professor da disciplina assumiu o papel de juiz, e os temas foram atribuídos como réus, cada subgrupo (defesa e acusação) tiveram 30 minutos para argumentarem e 20 minutos para realizar réplicas. Ao final, os jurados se reuniram e debateram entre si o tema para apontar um veredicto. O professor avaliou os alunos individualmente e em grupo, através da participação, entrosamento dos grupos, pesquisa dos dados e a postura frente às falas dos colegas. No resultado do estudo, foi demonstrado um feedback positivo na utilização do júri, principalmente, no terceiro período, no qual os alunos se empenharam na pesquisa e desenvolvimento de argumentos. Além disso, o conteúdo foi absorvido de forma eficiente e os alunos notaram a evolução em oratória, capacidade argumentativa e senso crítico.

\section{Discussão}

A utilização de metodologias ativas faz com que os estudantes ultrapassem o ensino tradicional empregado no método pedagógico atual, no qual o docente apenas repassa o conhecimento e não há interação entre aluno-professor. Por meio da MA, como o júri simulado, há mais diálogo entre os indivíduos do processo educacional, maior comprometimento no sistema educativo e desenvolvimento profissional e pessoal. Segundo o Lima et al., 2020, as MA são consideradas ferramentas excelentes no processo educacional, as quais são apoiadas na abordagem pedagógica e tendem a despertar interesse nos estudantes, aprimorando habilidades úteis para sua formação. Além disso, contribuem para o entendimento facilitado de temas complexos, fomentando a qualidade do ensino.

O júri simulado é classificado como MA para o desenvolvimento da argumentação científica, devido à pesquisa criteriosa realizada, elaboração de argumentos consolidados e posicionamento intelectual diante ao tema (Lima et al., 2020). Ademais, a simulação possui o papel fundamental de levar os estudantes para a realidade, enfrentando problemas e situações do mundo real, aflorando o pensamento crítico e reflexivo. Nota-se também a contribuição na percepção de preservar o respeito com outros indivíduos que apresentam posições distintas.

É visto que, diante das pesquisas citadas com feedback dos estudantes e dos docentes, o júri simulado é uma metodologia ativa que é eficaz no processo de ensino-aprendizagem. De acordo com Silva Filho et al., 2015, a simulação é um fator que estimula o raciocínio, reflexão, senso crítico, além dos princípios éticos e morais de cada profissão. É uma estratégia 
que permite o exercício de busca qualificada na literatura e exposição concreta dos dados obtidos (Lima et al., 2020 ). Nos primeiros dias da aplicação da MÁ percebe-se a timidez e a insegurança para a discussão, porém, através do júri os estudantes conquistam autonomia intelectual, superam as dificuldades da oratória e desenvolvimento de fatores associados à justiça, direitos e deveres do cidadão, bem como ética e moral profissionais.

Ressalta-se que de acordo com Santos \& Neto, 2021, o desempenho acadêmico (DA) depende intimamente da escolha da metodologia, como também, de fatores individuais, da prática pedagógica e método avaliativo. Na preferência pela MA, a qual auxilia o docente no processo avaliativo e desperta autonomia nos discentes, o DA resultante é mais positivo em relação à metodologia passiva. Além disso, a avaliação sobre a MA permite a fuga do aspecto somativo e oportunidade de uma avaliação formativa, a qual assente ao acadêmico a possibilidade de refletir sobre seus conhecimentos (Santos \& Neto, 2021)

Em cursos de saúde, como Medicina e Enfermagem são usados diversos tipos de MA, principalmente, o júri simulado, pois ele traz vivências reais para os alunos, preparando-os para lidar com a pressão da profissional. De forma infortuna, na Medicina Veterinária são poucos relatos do uso de MA de forma geral. Tal fato é preocupante, visto que é um curso que também lida com vidas, pressão ao trabalho e necessidade de tomada de decisões rápidas. Com base nisto, é visto que o júri simulado é uma boa ferramenta para desenvolver ensino intelectual nos cursos de veterinária, como também o ensino pessoal, através da adoção da simulação em disciplinas complexas e atribuindo situações existentes na rotina de um profissional.

\section{Considerações Finais}

É visto que as metodologias ativas vêm sendo utilizadas cada vez mais por professores e especialistas em educação, na intenção de aumentar a eficácia do aprendizado e também auxiliar no desenvolvimento do pensamento crítico e reflexivo dos alunos. Tal característica é de extrema importância para ser um profissional renomado no mercado competidor, principalmente nas profissões voltadas para a saúde.

O júri simulado é uma das MA mais utilizadas nos cursos de saúde, como na Medicina, Enfermagem, Odontologia e Medicina Veterinária, pois criam situações parecidas com a realidade, fazendo com que o aluno vivencie tais experiências antes de sua inserção no mercado de trabalho.

Na matéria de farmacologia da reprodução tal estratégia tem um bom potencial, pois é um assunto que possui muita ambiguidade de pensamentos e, além disso, são variáveis dependendo da situação apresentada. Com isso, nota-se a importância de os alunos terem esta visão e pensamento crítico para se tornarem profissionais renomados na área.

\section{Referências}

Abepirense, P. G. G. S., Vieira, G. O., \& Curtinhas, S. (2014) O uso de metodologias ativas na formação do profissional enfermeiro - Tribunal do júri simulado: uma experiência de sucesso. In: Congresso Ibero-americano de Ciência, Tecnologia, Inovação e Educação, Buenos Aires. Resumo de Trabalhos. Buenos Aires. Obtido 10 de Abril, 2021, em https://docplayer.com.br/32136633-O-uso-de-metodologias-ativas-na-formacao-do-profissional-enfermeirotribunal-do-juri-simulado-uma-experiencia-de-sucesso.html

Anastasiou, L. G. C., \& Alves, L. P. (2005). Processo de ensinagem na universidade: pressupostos para estratégias de trabalho em aula. Editoria Univille

Costa, H. X. (2011). A importância do médico veterinário no contexto de saúde pública. Seminário apresentado junto à Disciplina Seminários Aplicados do Programa de Pós-Graduação em Ciência Animal da Escola de Veterinária da Universidade Federal de Goiás. Nível: Doutorado. Obtido 9 de Junho, 2021, em https://files.cercomp.ufg.br/weby/up/67/o/Seminario2011_Herika_Costa_1.pdf

Reppold, D. P. (2021). Aprendizagem significativa em química orgânica por meio da temática autometicação. Trabalho de Conclusão de Curso - QUI” do Curso de Química da Universidade Federal do Rio Grande do Sul. Nível: Licenciatura. Obtido 13 de Junho, 2021, em https://www.lume.ufrgs.br/handle/10183/222738

Frias, R. B., Mariano, R,S,G., \& Pinheiro Junior, O. A. (2009). Importância do médico veterinário na saúde pública - revisão bibliográfica. Revista Científica Eletrônica de Medicina Veterinária,7(12), 23-29. Obtido em https://files.cercomp.ufg.br/weby/up/67/o/Seminario2011_Herika_Costa_1.pdf

Gil, A. C. (2013). Metodologia do Ensino Superior. São Paulo. Gen 
Research, Society and Development, v. 10, n. 12, e06101219866, 2021

(CC BY 4.0) | ISSN 2525-3409 | DOI: http://dx.doi.org/10.33448/rsd-v10i12.19866

Gomes, L, B. (2017). Importância e atribuições do médico veterinário na saúde coletiva. Sinapse Múltipla,.6(1),70-75. Obtido em http://periodicos.pucminas.br/index.php/sinapsemultipla/article/view/15426

Kleber, K., \& Trevisan, L. (2010). Produzindo capital humano. São Paulo: Editora Cultura.

Lemos do nascimento, J., \& Feitosa, R. A (2020). Metodologias ativas, com foco nos processos de ensino e aprendizagem. Research, Society and Development, 9(9), 62-75. doi: https://doi.org/10.33448/rsd-v9i9.7551

Lima, B. M., Verri, I. A., Soares, J. Y. S., \& Oliveira, S. V. (2020). Júri simulado como estratégia ativa de ensino de Vigilância em Saúde. Arq. Cienc. Saúde UNIPAR, Umuarama, 24(2), 125-129. doi: https://doi.org/10.25110/arqsaude.v24i2.2020.7634

Merlo, V. (2019). O uso de júri simulado como metodologia de ensino ativa. Nova escola. Obtido 9 de Abril ,2021, em https://novaescola.org.br/conteudo/18041/o-uso-de-juri-simulado-como-metodologia-de-ensino-ativa

Mongelli, M. S., Ferrante, M., \& Arcas, P. H (2020). O uso do júri simulado como metodologia ativa na medicina veterinária: eficiência do ensino na reprodução animal. Trabalho apresentado no V Congresso Inovação e Metodologias no Ensino Superior e Tecnológico. Obtido 14 de Julho, 2021, em https://congressos.ufmg.br/index.php/congressoeducacaoetecnologia/index/search/authors/view?firstName=Melissa\&middleName=Sanches\&lastName=Mong elli\&affiliation=Universidade $\% 20$ Federal $\% 20 \mathrm{de} \% 20$ Lavras $\% 20-\% 20$ UFLA\&country=BR

Oliveira, G., \& Faria, V. (2019) Metodologia ativa na educação em medicina veterinária. PUBVET, 13(5), 1-7. doi: https://doi.org/10.31533/pubvet.v13n5a335.1-7

Persad, G. C., Elder, L., Sedig, L., Flores, L., \& Emanuel, E. J. (2008). The current state of medical school education in bioethics, health law, and health economics. The Journal of Law, Medicine \& Ethics,36(1), 89-94. doi: https://doi.org/10.1111/j.1748-720X.2008.00240.x

Prado, L., \& Silva, M. (2017). Utilização de júri simulado com duas turmas do curso de Medicina Veterinária - Estudo de caso. UNISAL Lorena. II Congresso Internacional Salesiano de Educação. Obtido 10, 2021, em http://www.lo.unisal.br/sistemas/conise2017/anais/188_13500771_ID.pdf

Santos, F. A, \& Neto, I. C. P. (2021). Avaliação do desempenho de acadêmicos de odontologia no ensino superior sob metodologia ativa: percepções e vivências. Research, Society and Development,10(3), 59-71. doi: http://dx.doi.org/10.33448/rsd-v10i3.13805

Savari, S, P. K.., Reberte, A., Bortoluzzi, M. C., Schlemper Junior, B., \& Bonamigo É. L. (2013). Julgamento simulado como estratégia de ensino da ética médica. Revista Bioética, 21(1), 150-157. doi: https://doi.org/10.1590/S1983-8042201300010001

Silva Filho, C .C., Geremia, D. S., Oliveira, M. C., \& Sbardelotto, T (2015). O sistema único de saúde em julgamento: A experiência do júri simulado entre acadêmicos (as) recém-ingressos (as) em enfermagem. V Seminário de Ensino, Pesquisa e Extensão da UFPS, 5(1), 33-34. Obtido 13 de Junho, 2021, em https://portaleventos.uffs.edu.br/index.php/SEPE-UFFS/article/view/2956/1576

Veiga, L. A., \& Fonseca, L. R. (2018). O júri simulado como proposta didático-pedagógica para a formação inicial do professor de geografia na perspectiva da aprendizagem baseada em problemas (PBL). Geousp - Espaço e Tempo (Online), 22(1), 153-171. doi: http://dx.doi.org/10.11606/issn.2179-0892. geousp.2018.125843.

Vieira, R., Melo, V., \& Bernardo, J. (2014). O júri simulado como recurso didático para promover argumentações na formação de professores de física: O problema do "gato". Ensaio Pesquisa em Educação em Ciências, 16(3), 203-225. doi: - http://dx.doi.org/10.1590/1983-21172014160310

White, C.T. (2015). Using a Mock Trial Method to Enhance Effectiveness of Teaching Evidence-Based Practice in Nursing. Journal for Nurses in Professional Development,31(6), 11-14. doi: https://doi.org/10.1097 / NND.0000000000000214 